\title{
Does Emotional Intelligence Pave way for Psychological Well Being and Enhancing Work Performance
}

\author{
Rajeesh Viswanathan, Moiz Mohammed, N. Sarath Lal, Jahira Parveen
}

\section{Abstract:}

Purpose-Present study is a descriptive and analytical in nature aiming to bring out the relationship among emotional intelligence, cultural intelligence, perceived organizational supporting practices, family support on psychological wellbeing and work performance of the Indian expatriates in United States of America.

Design/Methodology/Approach- This study adopts positivist deductive approach it, starts with clear variables which are derived from theory and based on these variables. The data for the study was collected through the structured questionnaire. The sample for the present study was collected from the Indian IT expatriates who are assigned to USA working in the four major IT cluster of USA i.e. California, Washington, New York, \& Chicago. A total 634 questionnaires were received indicating a response rate of 52 $\%$. The questionnaire for this study consists of 87 items and the five point Likert type response format is used for all the measures ranging from strongly agree to strongly disagree. SPSS 21 and Microsoft excel are the statistical packages and regression is the tools used in the present study

Findings- An important affiliation was observed among emotional intelligence and expatriate job performance and psychological wellbeing. As the job performance and psychological wellbeing largely dependent on the emotional intelligence of the employee, the job performance of the expatriates is also influenced by the emotional intelligence level of the expatriate. Higher levels of emotional intelligence predict higher the job performance and psychological wellbeing of the expatriate. A significant relationship was found between cultural intelligence and expatriate job performance and psychological wellbeing. When the expatriate face culturally diverse work environment, the Cultural intelligence of the expatriate allows the expatriate to adopt behaviours which potentially contributes to the success of the expatriate in the diverse work environment.

A signification had been observed between perceived organizational supporting practices and expatriate performance. Inclination towards repayment towards the organization is high among the employees who are in receipt of major support from the organization. The support of the organization becomes more relevant in the instance of the expatriates because the expatriates are working away from the parent organization in culturally diverse settings. A signification relationship was found between perceived family supports and expatriate performance. When the accompanying family is well adjusted to the new culture, the employee can concentrate more on the job responsibilities. Hence,

Revised Manuscript Received on July 05, 2019

Dr. Rajeesh Viswanathan, Asst Prof, Dept of International Business, School of Management, Pondicherry University, Pondicherry, India.

Dr Moiz Mohammed, Associate Professor, Nawab Shah Alam Khan College of Engineering and Technology, Hyderabad. India

N. Sarath Lal, Dept of International Business, School of Management, Pondicherry University, Pondicherry, India.

Dr. Jahira Parveen, Faculty of Management, SRM Institute of Technology, Chennai, Tamilh Nadu, India the performance will be high. It is proved in the literature that work and family must be well balanced for an employee to be more effective.

No significant relationship was found between perceived organizational support and psychological wellbeing. The importance of the organizational support is essential for the employee well-being and the employees if they perceive that organization supports them in all facets of their work and family they will to be more productive and more committed to the organization. However, the study shows that the perceived organizational support does not significantly impact the psychological wellbeing. Sufficient evidence was not found for this proposition. No significant relationship was found between perceived family support and expatriate psychological wellbeing. $A$ well-adjusted family will have an important bearing on the psychological wellbeing of the expatriate.

Originality/value- This study provides insightful findings in understanding the role individual competencies like emotional intelligence and cultural intelligence play in facilitating expatriate job performance and psychological wellbeing i.e. from family and organization support in the individual level and work outcomes.. In spite of the limitations of the research, the study contributed to the international human resources management by exploring the Indian IT expatriates adaptation process in the western context.

Index Terms: Emotional Intelligence, Cultural Intelligence, Perceived Organizational Supporting Practices, Family Support Job Performance and Psychological Wellbeing.

\section{INTRODUCTION}

This study focuses on Indian IT expatriates working in the United States of America and their experiences and perceptions of their Psychological wellbeing, and work performance. The purpose of study was to investigate what are the individual level factors and organizational level factors which influence the psychological wellbeing and job performance of Indian IT expatriates. It looks at how the emotional intelligence, cultural intelligence, organizational supporting practices and family support influence the Psychological wellbeing, and Job performance of the expatriates.

Many MNCs have started operating in India due to the growth in IT industry and due to availability of the highly skilled man power. The Increase in globalization had led to more employees being sent on both short term and long-term international assignments than ever before as cited in (Hechnova, Beehr, \& Christiansen, 2003). International assignments can be extremely challenging (Hechnova, Beehr, $\&$ Christiansen, 2003). Deputing an employee onsite not only is of strategic importance but along with that the operating cost of that employee goes up

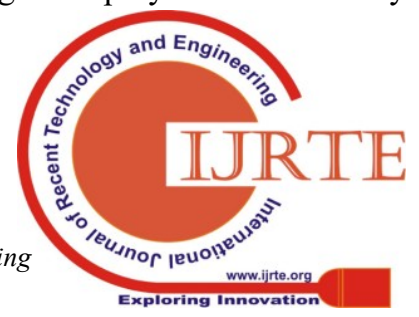


nearly four to five percentage. (Vallabh, Mishra \& Bhaitia, 2008). And if the employee underperform or quite then it will impact the project schedule and it might result in loss for the MNCs in the form of reputation with the client and also monitory losses. The Present study explores the influence that individual competencies like emotional intelligence, cultural intelligence and supporting systems like perceived organizational supporting practices and family support on work performance and psychological wellbeing of Indian IT expatriates who are on an international assignment in United States of America. This study will examine how the cross-cultural adjustment can contribute to the work performance and psychological wellbeing of the expatriate when on international assignment. The present study uses a quantative descriptive approach, to explore the phenomenon of adjustment in the host country among a sample of Indian MNC expatriates in United States of America.

Deci and Ryan came out with a new concept of well being which was an porch to subjective well being. (e.g., Ryan \& Deci, 2000, 2001) and Ryff (1989) which was on the basis of human desires and effective performance. It was coined as "psychological well being" and it is associated as a part of humanistic theories for affirmative functioning. It was learnt from couple of authors that it is dissimilar from subjective feelings of well being even though it over lapped empirically. On the other hand it is observed that subjective well-being is people's evaluations of their lives, whereas psychological well-being is thought to represent optimal human functioning. Work in an organization can make an employee extremely happy and on the other hand unhappy. It depends on the environment how conducive it is. A scenario where we try to motivate and instill ideologies among the employees is main process of psychological wellbeing. If the relationship is non conducive it creates exasperating feeling gets in a bamboozled situation between among employees which would hamper psychological wellbeing. It has been observed from various studies that work performance is closely interlinked with psychological wellbeing. Expatriates who are assignment on the foreign assignments due to cross cultural differences might face problems at work that might threaten their psychological wellbeing. Psychological well-being is given much importance in the domestic settings. It's also important to understand Psychological wellbeing expatriates who work in culturally diverse settings.

In the recent literature on the expatriates cross cultural adjustment and performance, much prominence is given to the role emotional intelligence. Emotional intelligence can be defined as "The abilities to understand and manage the emotional reactions of yourself and those of others and to effectively adapt in culturally diverse settings, have been increasingly recognized as critical elements that influence adjustment" as cited in (Lin, Chen, \& Song, 2012:542). "The ability to monitor one's emotional changes and accurately read the emotional reactions of others is called emotional intelligence." (Lin, Chen, \& Song, 2012: 542). There is enough evidence that emotional intelligence play an important role in the various facets of employee's work. The emotional intelligence assumes a significant role in the international assignments because of the nature of the international assignments. When an employee is selected and assigned to an international assignment, he or she face new culture, and new work practices which might cause significant problems to the international assignee to get adjusted to the new environment and it also will have a significant effect on the performance level of the employee. Under such instances "EI with its Dimensions are critical factors that facilitate adjustment when facing a different cultural environment." (Lin, Chen, \& Song, 2012: 545). Also (Lin, Chen, \& Song, 2012: 544) argues that "EI and its dimensions as a predictor of cross-cultural adjustment." The present study is an attempt to examine the effects of emotional intelligence on cross cultural adjustment, psychological wellbeing, Intention to finish the assignment and expatriate job performance.

One of the important ability to be successful in the globalized world is the ability to socialize with colloquies from multifarious background. The importance of the cultural intelligence has grown enormously because of the diversity in work force and because of the increase in international mobility due to globalization. An expatriate may faces number of problems when working in a culturally diverse country and workplace. In order to cope up with such problems and adjust successfully the expatriate needs certain abilities. "CQ refers to the ability to collect and process messages, to make decisions, and the relative approaches needed in order to adjust to a new environment." (Lin, Chen, \& Song, 2012:542). "Cultural intelligence refers to individual capacities which enable one to interact effectively with others from different cultural backgrounds and in different cultural contexts" (MacNab \& Worthley, 2012:63). "Earley and colleagues developed a three-part model of cultural intelligence with cognitive/meta-cognitive, motivation, and behavior components" as cited in (MacNab \& Worthley, 2012). "Cultural intelligence [cultural quotient (CQ)] is the ability of individuals to acquire, store, and use cultural knowledge" as cited in (Wua \& Ang, 2011: 2684). (Lin, Chen, \& Song, 2012: 542) stated that there is a need to enhance a persons CQ and EI which would help them to adapt to work, and their ability to deal with general living conditions in a cross-cultural context. "Cultural Intelligence is one of the key determinates of expatiate success" (Lin, Chen, \& Song, 2012: 542) \& (Wua \& Ang, 2011: 2684).Expatriates who have to work in the culturally diversified workforce and country have to develop this special skill to be better adjusted and more productive. The present study is an attempt to examine the effects of cultural intelligence on cross cultural adjustment, psychological wellbeing, Intention to finish the assignment and expatriate job performance.

"POS corresponds to the level to which an organization is opting to pay off employees for their hard work, facilitate them with conducive working environment and stress free work" as cited in (Erturk \& Vurgun, 2015:37). "Once an employee is taken care by the organization with descent motivational factors, it is imperative that employee would be engaged with the organization and obliged to repay the organization. One ideal approach to reciprocate the organization's favorable treatment is through continued participation" as cited in (Erturk \& Vurgun, 2015:37). The importance of the organizational support is essential for the employee well-being and the employees if they perceive that organization supports them in all facets of their work and family they will to be more productive and more committed to the organization. The support of the organization becomes more relevant in the instance of the expatriates because the expatriates are working away from the parent organization 
in culturally diverse settings. "Expatriate supporting practices typically include a series of human resource supporting practices in international assignments, we recognize those supporting practices as a bundle, as suggested by prior research in the human resource management literature" as cited in (Wua \& Ang, 2011: 2684). Therefore, this study also focuses on the expatriate supporting practices as perceived by the employees. The present study is an attempt to examine the effects of Perceived organizational supporting practices on cross cultural adjustment, psychological wellbeing, Intention to finish the assignment and expatriate job performance.

"Expatriate assignments often involve either uprooting families to a new country or causing the expatriates to live away from their families-either of which puts strain on both expatriates and their families" (Hechnova, Beehr, \& Christiansen, 2003). "Expatriate adjustment has been strongly related to non-work factors such as psychological orientations, attitudes towards international living and family-related problems" (Osman-Gani \& Rockstuhl, 2009:279). The expatriate cross cultural adjustment largely depends on the family support and the social support in the host country. The present study is an attempt to examine the effects of Perceived family support on cross cultural adjustment, psychological wellbeing, Intention to finish the assignment and expatriate job performance.

Job performance has been defined as "the aggregate value to the organization, of the discrete behavioral episodes that an individual performs over a standard interval of time" (Borman \& Motowildo, 1997). (Borman \& Motowildo, 1997) has divided the Job performance into two distinct dimensions i.e. task performance and contextual performance. "Task performance is concerned with formally defined prescribed behaviors distinct to specific to job that contributes to the organizational technical core" (Borman \& Motowildo, 1997). "Contextual performance include extra role behaviors supporting broader social and psychological environments encompassing the technical role of the organization, which are not explicitly included in the list of formal job responsibilities and obligations" (Borman \& Motowildo, 1997). (Osman-Gani \& Rockstuhl, 2009:277) argued that "One of the major determinants of expatriate performance effectiveness is how well they adjust themselves to function appropriately in the host culture." Both task performance and contextual performance are important for the success of the organization and the individual employee performance. Contextual performance assumes an important role in the case of expatriates because it involves social interactions and the expatriates have to adjust to the new culture and the have to work in the culturally diversified workplace. Because of the relevance and significance of these, the study focuses on the role of emotional intelligence, cultural intelligence perceived organizational supporting practices, family support on expatriate adjustment psychological wellbeing Intention to finish the assignment and job performance.

\section{Purpose of the Study}

Present study is a descriptive and analytical in nature aiming to bring out the relationship among emotional intelligence, cultural intelligence, perceived organizational supporting practices, family support on psychological wellbeing and work performance of the Indian expatriates in United States of America.

\section{RATIONALE}

When an expatriate is assigned to country with is culturally different the expatiate employee may experience cultural difference and this may impact his adjustment to the new environment and it may further impact his psychological wellbeing and the performance. Number of MNCs operating in India sends the employee to the overseas assignments for the undertaking projects. Therefore, there is a need to study the impact of individual level competencies like emotional intelligence, cultural intelligence, perceived organizational supporting practices and perceived family support which impact the psychological wellbeing and work performance of Indian expatriates working in culturally diverse country like United States of America. This aim of the study is to provide into insights that will help the MNCs in selection and training expatiates for optimal performance and the employee psychological wellbeing and Work Performance

\section{SIGNIFICANCE OF THE STUDY}

On a general level, this study will have significant value for Indian expatriates investing time in United States of America, because this research thoroughly covers past and present cultural and business analysis trends in Saudi Arabia.

1. The observations of this research would enlighten policy makers in the top management of Indian companies to make effective decisions that support and fund effective expatriation programs.

2. The research and its observations will also update international research on Indian expatriation and psychological wellbeing as well as job performance

\section{SCOPE OF THE PRESENT STUdY}

This study is confined to the IT industries and the respondents are the Information Technology expatriates assigned to United States of America on short time and long term assignments on client side or in subsidiary offices of the MNC. The research study focuses on impact of emotional intelligence, cultural intelligence, perceived organizational supporting practices and perceived family support on psychological wellbeing and work performance. Hence, the study is confined to the study variables only.

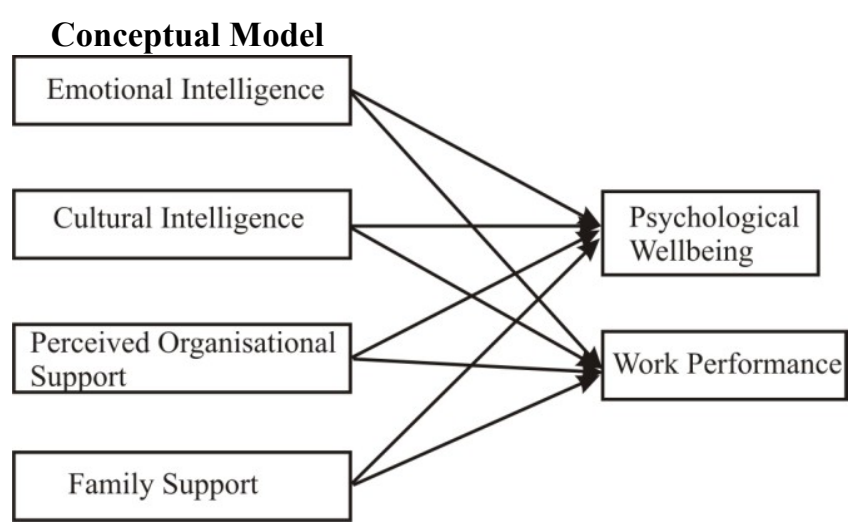




\section{Objectives}

- To understand the relationship of emotional intelligence, cultural intelligence, perceived organizational support, perceived family support with work performance of Indian Information technology expatriates in United States of America.

- To understand the relationship of emotional intelligence, cultural intelligence, perceived organizational support and perceived family support with psychological wellbeing of Indian Information technology expatriates in United States of America.

\section{Hypothesis Development}

H1: There is no significant relationship between emotional intelligence, and expatriate work performance

H2: There is no significant relationship between cultural intelligence and expatriate cross-cultural work performance H3: There is no significant relationship between perceived organizational support and expatriate cross-cultural work performance.

H4: There is no significant relationship between perceived family support and expatriate cross-cultural work performance.

H5: There is no significant relationship between emotional intelligence, and expatriate psychological wellbeing.

H6: There is no significant relationship between cultural intelligence and expatriate psychological wellbeing.

H7: There is no significant relationship between perceived organizational support and psychological wellbeing.

H8: There is no significant relationship between perceived family support and expatriate psychological wellbeing.

\section{Research Design}

This study adopts positivist deductive approach it, starts with clear variables which are derived from theory and based on these variables, testable hypothesis were framed and tested. This study uses quantitative approach since all the variables in the study are quantifiable. The data for the study was collected through the structured questionnaire. The study aims to contribute to the literature on expatriate management and international human resource management in general. This study is descriptive in nature. The aim of the study is to find causes and relationships between the variables of interest. The study addresses the descriptive to what extent? Since the study involves larger samples, primary data was collected by using survey method. The objective is to understand the perceived impact of emotional intelligence, cultural intelligence, perceived organizational support, perceived family support on psychological wellbeing and work performance of the expatriates. In order to fulfil the study objectives the study employed appropriate methodology.

\section{Survey Method}

It is a method to collect the data using questionnaires or interview methods for recording the conversations of the researcher and the employee during the process (Ghauri \& Gronhaug, 2005). When researcher collects the data from a set of respondents by interacting with them. This process is know as survey method (Maylor \& Blackmon, 2005). (Zikmund, 2003) have termed is as a strategy to collect the primary data from the respondents to enable the research activities." Survey is a process through which we collect the data through a highly systematic way by adopting highly structured questionnaire through interview or non interview techniques (Cooper \& Schindler, 2006). In survey research needs to interview the respondents to seek their perception about the situation in either verbal or written format (Zikmund, 2003).Surveys are especially useful for capturing facts, opinions, behaviors, or attitudes (Maylor \& Blackmon, 2005).Questionnaires, structures interviews are most commonly used tools in survey research design (Maylor \& Blackmon, 2005). Surveys can be quick, inexpensive, efficient, and accurate means of assessing information about the population (Zikmund, 2003). Survey can be useful especially when we want to collect data from a large number of respondents and have limited time for collecting data and when the respondent cannot be reached directly (Maylor \& Blackmon, 2005). Due to the usefulness of survey method and also based on the previous studies this study adopted survey method to collect the data( see Harrison, \& Shaffer, 2007; Shaffer, Kraimer, Chen, Bolino, \& Chen, 2012). Majority of the researchers used the survey method to carry out the research in cross culturalt context. Therfore this study used survey method to carry out research.

\section{Population and Sample}

Given the current research focuses on the Indian IT professional expatriates who are currently working on site in USA and who's parent company is based in India, based working on international assignments either at a client site or a branch office in United States of America. In the present study, Indian IT expatriates assigned on the international assignments to United States of America form the sample unit. The sampling technique used for this study is Multistage Random Sampling method (Kothari C.R., 2004).

The sample for the present study was collected from the Indian IT expatriates who are assigned to USA working in the four major IT cluster of USA i.e. California, Washington, New York, \& Chicago. These four states were selected as they were considered the largest IT clusters by the U.S. Cluster Mapping Project. The HR managers of the companies operating in these four regions were approached using networks of the researcher and questionnaires were handed over to the HR managers to be distributed to the Indian IT employees who assigned to the international assignment. The HR managers distributed the questionnaires and collected data and the research collected back the questionnaires from the HR managers of the companies. A total 1200 questionnaires were distributed among the four IT clusters (300 hundred in each cluster) accompanied by a letter emphasizing the confidentiality and anonymity of responses. A total 634 questionnaires were received indicating a response rate of $52 \%$ which is considered a good response rate due to the nature of the study. Out of the 634 questionnaires, received 111 questionnaires were discarded due to missing data. 525 questionnaires were used for the final study.Of which comprised of 188 females (40 percent) and 282 males (60 percent). It was observed that in the current study 32 was the average age of most of the respondents and possessing minimum under graduate degree. It was further seen that though the respondents experience ranged from 05 to 10 but on an average possessed 07 years.

Descriptive and analytical research design is used and data were collected from 523 IT expatriates working in USA through structured questionnaire. 


\section{Research Tools and Software Package Used}

Research tools are statistical methods used for data analysis and to arrive substantial inferences. SPSS 21, Microsoft Excel are the statistical packages used in the present study and the following statistical tools were used to analyze the data.

\section{Measures}

Work performance: The expatriate performance (Caligiuri, 1997; Motowidlo \& Seotter, 1994).It is a 17 item scale and measures three dimensions namely overall performance, contextual performance and task performance. The participants were asked to rate each item on a 5 point- Likert scale from 1 (strongly disagree) to 5 (strongly agree). In the current sample, the Cronbach alpha for the instrument was 0.919 .

Psychological wellbeing: It was calculated by scale consisting of 8 Items developed by Diener, E., Wirtz, D., Tov, W., Kim-Prieto, C., Choi, D., Oishi, S., \& Biswas-Diener, R. (2009). The participants were asked to rate each item on a 5 point- Likert scale from 1 (strongly disagree) to 5 (strongly agree). In the current sample, the Cronbach alpha for the instrument was 0.915 .

Emotional intelligence: It was calculated with 16 item scale developed by Wong, C. S., \& Law, K. S. (2002).It is a 16 item instrument and assesses four dimensions, namely self-emotional appraisal, others emotional appraisal, use of emotions, and regulation of emotions. Respondents were asked to state their perception about the research on a 5 pointLikert scale from 1 (strongly disagree) to 5 (strongly agree). If the scores were high it showed higher cultural intelligence. In the current sample, the Cronbach alpha for the instrument was 0.969

Cultural intelligence: in the study a 20 item scale developed by Ang et al (2007) was developed to measure cultural intelligence. This scale assess from four dimensions, namely cognitive dimension, meta cognitive dimension, behavioral dimension and motivational dimension of cultural intelligence Respondents were asked to state their perception about the research on a 5 point- Likert scale from 1(strongly disagree) to 5 (strongly agree).. if the scores were high it showed higher cultural intelligence. In the current sample, the Cronbach alpha for the instrument was 0.977

Perceived organizational support: This was measured using a 12 items scale developed by (Kraimer \& Wayne, 2004). It measured the employees from the three dimensions namely financial support, career support, and adjustment support. Respondents were asked to state their perception about the research on a 5 point- Likert scale from 1(strongly disagree) to 5 (strongly agree). If the scores were high it showed high cultural intelligence existing. In the current sample, the Cronbach alpha for the instrument was 0.968

Perceived family support: The spousal social support was measured with 8 items scale developed by (Vinokur and van Ryn, 1993). The 8 -item scale measure the perceived family/spousal support during the international assignment. The participants were asked to rate each item on a 5 pointLikert scale from 1 (strongly disagree) to 5 (strongly agree). In the current sample, the Cronbach alpha for the instrument was 0.933

\section{Pilot study}

The questionnaire was checked and compounded with Indian IT expatriates those who are working in the United States of America before carrying out the main study. This was to ensure correction of any ambiguities in the measurements as well as capturing correctly the concepts used in the study. After carrying out the pilot study the following changes were incorporated in questionnaire to make it more easier to infer and also to serve the purpose. Based on the feedback given by the respondents, minor corrections are made in the questionnaire.

\section{Reliability and Validity}

It is the true variance to the total variance yielded by the measuring instrument. It shows the steadiness and the internal uniformity of a test. 'Goodness' of a measure is assessed through checking the reliability. It shows the stability and consistency of the instrument . A measure is reliable to the degree that it supplier consistent results. measures represent the concept of the study and the degree to which it is free from any random error (Hair, Black, Babin, \&Anderson, 2010). Validity could be defined as the extent to which the set of Validity testing refers to as testing the ability of the instrument to measure the particular construct.

\begin{tabular}{|c|l|c|c|c|c|}
\hline $\begin{array}{c}\text { S. } \\
\text { No }\end{array}$ & \multicolumn{1}{|c|}{ Construct } & $\begin{array}{c}\text { No of } \\
\text { Items }\end{array}$ & $\begin{array}{c}\text { Reliability } \\
\text { (Cronbach's } \\
\text { alpha) }\end{array}$ & $\begin{array}{c}\text { Composite } \\
\text { Reliability }\end{array}$ & AVE \\
\hline 1 & Emotional Intelligence & 16 & 0.969 & 0.972 & 0.686 \\
\hline 2 & Cultural Intelligence & 20 & 0.977 & 0.979 & 0.700 \\
\hline 3 & $\begin{array}{l}\text { Perceived organizational } \\
\text { supporting practices }\end{array}$ & 12 & 0.968 & 0.972 & 0.742 \\
\hline 4 & Perceived family support & 8 & 0.933 & 0.946 & 0.748 \\
\hline 5 & Work Performance & 17 & 0.978 & 0.980 & 0.744 \\
\hline 6 & Psychological wellbeing & 8 & 0.915 & 0.931 & 0.629 \\
\hline
\end{tabular}

Cronbach's Alpha coefficient of all the variables in the study of Indian IT expatriates in United States of America has been projected in the table presented above. The overall Cronbach's Alpha coefficient is 0.913 , which indicates the high reliability of data. Validity is measured by Average Variance Extracted (AVE). The constructs with has AVE value of above 0.50 possesses convergent validity. In the above table, it can be clearly seen that the AVE values of all the constructs are above 0.50

\section{Normality}

Larger deviations of data form normal distribution affects the results and all the resulting statistics become invalid(Hair, Black, Babin, \& Anderson, 2010). Hence, it is important to test the normality of the data. Normality test are used to check whether the data set is normally distributed. It is imperative for normality test to obtain skewness and kurtosis of the data. Skewness instrument is applied in distribution analysis as a sign of asymmetry and deviation from a normal distribution. Skewness is the extent to which a variable's distribution is symmetrically around its mean value. If the data is normally distributes the values of skewness should fall within +2 to -2 range. Kurtosis instrument is used in distribution analysis as a sign of flattening of a distribution. Kurtosis is a measure of whether the distribution is too peaked. The values of kurtosis also should fall within +2 to -2 range when the data are normally distributed. 
Skewness and kurtosis

\begin{tabular}{|l|c|c|c|}
\hline \multicolumn{4}{|c|}{ Descriptive Statistics } \\
\hline & $\mathrm{N}$ & Skewness & Kurtosis \\
\hline & Statistic & Statistic & Statistic \\
\hline $\begin{array}{l}\text { Emotional } \\
\text { Intelligence }\end{array}$ & 523 & -0.243 & -1.601 \\
\hline $\begin{array}{l}\text { Cultural } \\
\text { Intelligence }\end{array}$ & 523 & -0.081 & -1.719 \\
\hline $\begin{array}{l}\text { Perceived } \\
\text { Organizational } \\
\text { Support }\end{array}$ & 523 & -0.265 & -1.661 \\
\hline $\begin{array}{l}\text { Perceived Family } \\
\text { Support }\end{array}$ & 523 & -0.232 & -1.549 \\
\hline $\begin{array}{l}\text { Work } \\
\text { Performance }\end{array}$ & 523 & -0.315 & -1.527 \\
\hline $\begin{array}{l}\text { Psychological } \\
\text { Wellbeing }\end{array}$ & 523 & -0.54 & -1.265 \\
\hline Valid N & 523 & & \\
\hline
\end{tabular}

\section{Multiple Regression Model}

A multiple regression model for various dependent variables in study was developed with the independent constructs.

Work Performance predicated by emotional intelligence, cultural intelligence, perceived organizational support, perceived family support, Work Adjustment, General Adjustment.

\begin{tabular}{|l|l|}
\hline & \multicolumn{1}{|c|}{ Hypothesis } \\
\hline H1 & $\begin{array}{l}\text { There is no significant relationship between emotional } \\
\text { intelligence, and expatriate work performance }\end{array}$ \\
\hline H2 & $\begin{array}{l}\text { There is no significant relationship between cultural } \\
\text { intelligence and expatriate cross-cultural work performance. }\end{array}$ \\
\hline H3 & $\begin{array}{l}\text { There is no significant relationship between perceived } \\
\text { organizational support and expatriate cross-cultural work } \\
\text { performance. }\end{array}$ \\
\hline H4 & $\begin{array}{l}\text { There is no significant relationship between perceived } \\
\text { family support and expatriate cross-cultural work } \\
\text { performance. }\end{array}$ \\
\hline
\end{tabular}

\section{Match summary}

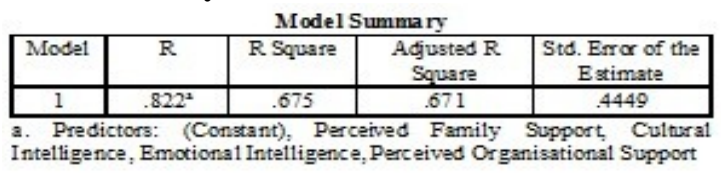

\section{Interpretations:}

$\mathrm{R}$ is the correlation, its value is 0.822 and $\mathrm{R}$ square is the degree of determination, its value is 0.675 . The degree of determination show the extent to which emotional intelligence, cultural intelligence, perceived organizational support, perceived family support influence Work performance. Here the work performance is determined to an extent of $67 \%$ by emotional intelligence, cultural intelligence, and perceived organizational support, and perceived family support.

\section{Anova Table:}

\begin{tabular}{|c|c|c|c|c|c|c|}
\hline \multicolumn{7}{|c|}{ ANOVA $^{2}$} \\
\hline & Mode1 & Sum of Squares & $\mathrm{df}$ & Mean Square & F & Sig. \\
\hline \multirow{3}{*}{1} & Regression & 212.072 & 6 & 35.345 & 178.579 & $.000^{2}$ \\
\hline & Residval & 102.130 & 516 & .198 & & \\
\hline & Total & 314.202 & 522 & & & \\
\hline
\end{tabular}

ANOVA table shows that the significant value is less than 0.01 , which means the dependent variable that is work adjustment is significantly predicted by the independent variables namely emotional intelligence, cultural intelligence, perceived organizational support, perceived family support at $99 \%$ confidence level.

\begin{tabular}{|c|c|c|c|c|c|c|}
\hline \multicolumn{7}{|c|}{ Coefficients ${ }^{2}$} \\
\hline & \multirow[t]{2}{*}{ Model } & \multicolumn{2}{|c|}{ Unstandardized Coefficients } & \multirow{2}{*}{$\begin{array}{c}\begin{array}{c}\text { Standardized } \\
\text { Coefficients }\end{array} \\
\text { Beta }\end{array}$} & \multirow[t]{2}{*}{$\mathrm{t}$} & \multirow[t]{2}{*}{ Sig. } \\
\hline & & $\bar{B}$ & Std. Error & & & \\
\hline \multirow{5}{*}{1} & $\overline{\text { (Constant) }}$ & -.325 & .152 & & -2.132 & .033 \\
\hline & Emotional Intelligence & .113 & .030 & .117 & 3.715 & .000 \\
\hline & Culnral Intelligence & .110 & .028 & .120 & 3.938 & .000 \\
\hline & $\begin{array}{l}\text { Perceived } \quad \text { Organisational } \\
\text { Support }\end{array}$ & .219 & .029 & 248 & 7.586 & .000 \\
\hline & Perceived Family Support & .082 & .022 & .098 & 3.775 & .000 \\
\hline
\end{tabular}

Work adjustment $=-0.325+0.113$ (Emotional Intelligence $)+0.110($ Cultural Intelligence $)$ +0.219 (Perceived organisational support) +0.082 (Perceived family support)

Among the above four factors perceived organizational support have a significant and highest impact on the work performance of the Indian IT expatriates in United States of America. Perceived family support is also significantly impacting the work performance of the IT expatriates in United States of America. Both emotional intelligence and cultural intelligence are also equally showing significant impact on the work performance of the Indian IT expatriates in United States of America. According to the above model hypothesis [H1] is rejected and it shows that there is a significant relationship between emotional intelligence, and expatriate work performance. Hypothesis [H2] is rejected and shows that there is a significant relationship between cultural intelligence and expatriate cross-cultural work performance. Hypothesis [H3] is rejected and it shows that there is a significant relationship between perceived organizational support and expatriate cross-cultural work performance. Hypothesis [H4] is rejected and shows that there is a significant relationship between perceived family support and expatriate cross-cultural work performance.

\section{Psychological wellbeing predicated by emotional intelligence, cultural intelligence, perceived organizational support, perceived family support, Work Adjustment, General Adjustment.}

\begin{tabular}{|l|l|}
\hline H5 & $\begin{array}{l}\text { Hypothesis } \\
\text { between emotional intelligence, and } \\
\text { expatriate psychological wellbeing. }\end{array}$ \\
\hline H6 & $\begin{array}{l}\text { There is no significant relationship } \\
\text { between cultural intelligence and } \\
\text { expatriate psychological wellbeing. }\end{array}$ \\
\hline H7 & $\begin{array}{l}\text { There is no significant relationship } \\
\text { between perceived organizational } \\
\text { support and psychological wellbeing. }\end{array}$ \\
\hline H8 & $\begin{array}{l}\text { There is no significant relationship } \\
\text { between perceived family support and } \\
\text { expatriate psychological wellbeing. }\end{array}$ \\
Published By: \\
Blue Eyes Intelligence Engineering \\
\& Sciences Publication
\end{tabular}


Match summary

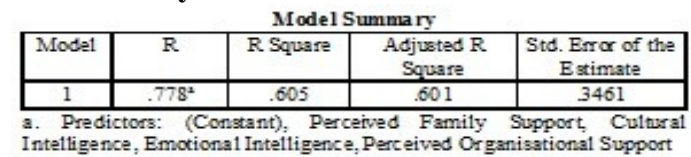

Interpretations:

$\mathrm{R}$ is the correlation, its value is 0.778 and $\mathrm{R}$ square is the degree of determination, its value is 0.605 . The degree of determination show the extent to which emotional intelligence, cultural intelligence, perceived organizational support, perceived family support influence Work performance. Here the work performance is determined to an extent of $60 \%$ by emotional intelligence, cultural intelligence, perceived organizational support, and perceived family support.

\section{Anova Table:}

\begin{tabular}{|c|c|c|c|c|c|c|}
\hline \multicolumn{7}{|c|}{ ANOVA } \\
\hline & Made1 & Sum of Squares & df & Mean Square & F & Sig. \\
\hline \multirow{3}{*}{1} & Regression & 94.824 & 6 & 15.804 & 131.968 & $.000^{2}$ \\
\hline & Residual & 61.794 & 516 & .120 & & \\
\hline & Total & 156.618 & 522 & & & \\
\hline
\end{tabular}

. Predictors: (Constant, Perceived Family Support, Cu Itural Intelligence, Emotional Intelligence, Perceived Organisational Support

ANOVA table shows that the significant value is less than 0.01 , which means the dependent variable that is work adjustment is significantly predicted by the independent variables namely emotional intelligence, cultural intelligence, perceived organizational support, and perceived family support at $99 \%$ confidence level.

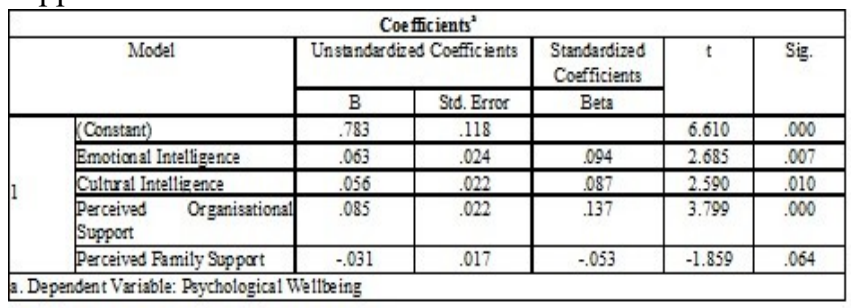

Work adjustment $=0.783+0.063($ Emotional Intelligence $)+0.056($ Cultural Intelligence $)$ +0.085 (Perceived organisational support)-0.031(Perceived family support)

Among the above four factors Perceived organizational support have impact on the psychological wellbeing of the of the Indian IT expatriates in United States of America. Perceived family support is not showing any significant impact on the psychological wellbeing of the IT expatriates in United States of America. Emotional intelligence is also equally showing significant impact on the psychological wellbeing of the Indian IT expatriates in United States of America. According to the above model hypothesis cultural intelligence is also showing impact on the on the psychological wellbeing. According to the model hypothesis, [H1] is rejected there is a significant relationship between emotional intelligence, and expatriate psychological wellbeing. Hypothesis [H2] is also rejected and it shows that there is a significant relationship between cultural intelligence and expatriate psychological wellbeing. Hypothesis [H3] is rejected and it shows that here is a significant relationship between perceived organizational support and psychological wellbeing. Hypothesis [H4] is accepted and there is no significant relationship between perceived family support and expatriate psychological wellbeing.

\section{Findings}

\section{Objective I:}

To understand the relationship of emotional intelligence, cultural intelligence, perceived organizational support, perceived family support, work adjustment, general adjustment with work performance of Indian Information technology expatriates in United States of America

\begin{tabular}{|l|l|c|}
\hline & \multicolumn{1}{|c|}{ Hypothesis } & Result \\
\hline H1 & $\begin{array}{l}\text { There is no significant relationship between emotional intelligence, and } \\
\text { expatriate workperformance }\end{array}$ & Rejected \\
\hline H2 & $\begin{array}{l}\text { There is no significant relationship between cultural intelligence and } \\
\text { exparriate cross-cultural work performance. }\end{array}$ & Rejected \\
\hline H3 & $\begin{array}{l}\text { There is no significant relationship between perceived organizational } \\
\text { support and expartiate cross-cultural work performance. }\end{array}$ & Rejected \\
\hline H4 & $\begin{array}{l}\text { There is no significant relationship between perceived family support and } \\
\text { expatriate cross-cultural work pefformance. }\end{array}$ & Rejected \\
\hline
\end{tabular}

A significant relationship was found between emotional intelligence and expatriate job performance. As the job performance largely dependent on the emotional intelligence of the employee, the job performance of the expatriates is also influenced by the emotional intelligence level of the expatriate. Higher levels of emotional intelligence predict higher the job performance of the expatriate. A significant relationship was found between cultural intelligence and expatriate job performance. When the expatriate face culturally diverse work environment, the Cultural intelligence of the expatriate allows the expatriate to adopt behaviours which potentially contributes to the success of the expatriate in the diverse work environment.

A signification relationship was found between perceived organizational supporting practices and expatriate performance. Inclination towards repayment towards the organization is high among the employees who are in receipt of major support from the organization The support of the organization becomes more relevant in the instance of the expatriates because the expatriates are working away from the parent organization in culturally diverse settings. A signification relationship was found between perceived family supports and expatriate performance. When the accompanying family is well adjusted to the new culture, the employee can concentrate more on the job responsibilities. Hence, the performance will be high. It is proved in the literature that work and family must be well balanced for an employee to be more effective.

Objective II:

To understand the relationship of emotional intelligence, cultural intelligence, perceived organizational support, and perceived family support, work adjustment, general adjustment with psychological wellbeing of Indian Information technology expatriates in United States of America. Hypothesis - H5, H6 are rejected and H7 and H8 are accepted. A significant relationship was found between emotional intelligence, and expatriate psychological wellbeing. Emotional intelligence also plays an important role in the psychological wellbeing of the expatriate employee. A significant relationship was found between cultural intelligence and expatriate psychological wellbeing. As psychological wellbeing largely depends on the adjustment of the expatriate in the diverse culture. The higher levels of cultural intelligence help the expatriates to have higher level of psychological wellbeing.

No significant relationship was found between perceived organizational support and psychological wellbeing. The importance of the organizational support is essential for the employee well-being and the employees if they perceive that organization supports them in all facets of their work and family they will to be more 
productive and more committed to the organization. However, the study shows that the perceived organizational support does not significantly impact the psychological wellbeing. Sufficient evidence was not found for this proposition.

No significant relationship was found between perceived family support and expatriate psychological wellbeing. A well-adjusted family will have an important bearing on the psychological wellbeing of the expatriate.

\section{Contribution of the Study}

This study suggests that the individuals with high levels of cultural intelligence are easily adjusted to the cross cultural setting and they are more capable to overcome cultural barriers. One of the important strategies of the MNCs is to select the candidate for international assignment who has high levels of cultural intelligence. The study contributes to the body of knowledge on international human resources management and organizational support. This study shows that organizational support plays an important role in cross cultural adjustment and performance of an expatriate employee. The MNCs can design appropriate support programs to give constant support to the expatriates who are sent on international assignment. This study contributes by giving number of suggestion to the individual employee who are selected for international assignments and to the individuals who might be potentially sent on the international assignment in near future. The results of the study provides insights to the employees who are about to take on the international assignments. They can prepare themselves to overcome cross cultural barriers and get adapted to the new culture and work effectively in the cross cultural settings.

\section{Implications and Suggestions}

When people move across cultures and countries, a global perspective in management theory is critical (Earley \& Ang, 2003).Cultural environment comprises of institutions and other forces that affect society's basic values, perceptions, work ethics, preferences, and behaviors. Individual grow up in different environment and this environment shapes their behavior and value system. Culture of an individual is based on the socio economic environment in which the invididual is born and brought up. Its on this basis the ethics are build up and which has direct impact on the performance of the employees either at work or in society. This study contributes to the theory of culture by findings that shows that cultural intelligence theory developed by (Earley, 2002)(Wu \& Ang, 2011) have important implication for cross cultural adjustment and work performance in cross cultural context.

According to organizational support theory which supposes that employee, infer the extent to which the organizations cares about their wellbeing through various polices, practices, and treatments. Employees then will reciprocate such support with increased loyalty and performance (Rhoades \& Eisenberger, 2002). The result of the study indicate that the perceived organizational support have an significant impact on all the outcomes like work performance, intention to finish the assignment, however the study found no significant relationship between the perceived organizational support and psychological wellbeing. Perceived organizational support (POS) is also valued as assurance that aid will be available from the organization when it is needed to carry out one's job effectively and to deal with stressful situations(Rhoades \& Eisenberger, 2002).(Eisenberger, Stinglhamber, Vandenberghe, Sucharski, \& Rhoades, 2002) argue that Organizational support theory is expected to facilitate organization's readiness where by employees can be rewarded to enhance work effort and overcome their socioemotional needs, employees develop global beliefs concerning the extent to which the organization values their contributions and cares about their well-being. The perceived support given by the organization to the family adjustment also impacts the performance of the expatriate. The result of the study indicate that the perceived organizational support have an significant impact on all the outcomes work performance, intention to finish the assignment, however the study found no significant relationship between the perceived organizational support and psychological wellbeing. The results of the study support the organizational support theory proposed by (Eisenberger et al., 2002).

MNCs often use the employees to work in culturally diverse environments due the nature of international business in the present globalized world. MNC are sending the employees on international assignment to take care of the business interests, knowledge transfer and to provide client support. These MNCs which are sending employees on international assignments should take care that they remove anxieties related to career, financial, and adjustment related concerns, so that they can concentrate on the work and performance to their maximum potential in the cross cultural context.

MNCs should have policies worldwide regarding the fair and equal treatment of all employees. The MNCs should also be sure the policy is communicated through all the culturally appropriate channels. Train employees on policies. Also, the MNCs should reward the HR managers who are promoting the policies. MNCs should offer mechanism to improve the likelihood that the spouses of the expatriates will adjust well cross culturally. Cross cultural training for spouses is also needed. There is always a chance that the spouses need will not match what being offered by the MNCs. Financial assistance for professional and personal development must be provided.

Training is also important for employees going overseas. At a minimum, it is necessary to give briefings on culture and language. Even simple things like when to shake hands, what to say upon on introduction, and what basic language rituals are used each day should be learned. Training is also important in hiring foreign nationals to work in the overseas office. It sometimes takes several months or longer to inoculate the firm's culture, ethics, and values in a foreign national. This is especially important in emerging and transition economies that have much different cultural and commercial traditions, and very little experience with doing business outside of their own regions. Remember the importance of experience when selecting the managers, particularly for a foreign assignment. What type of organization did the candidate work in before? What type of international experience does he or she have, including experiences during school?

\section{Limitations}

Limitations of the study are based on the previous empirical researches done. Other than that a few as given below

- Only one country is chosen for the study and results may not be generalized to the other countries. 
- Observation and Interview method is not possible in the study because of the geographical distance.

- Cross Sectional design may hamper the applicability of the causal conclusions drawn from our findings.

- There could be bias in the responses as all the responses are based on the perception of the respondents.

\section{Suggestion for Future Research}

Future studies must try to include to collect data from various other sources such as spouses of expatriates and children of the expatriates, colleagues, and supervisors. In the future, more instead of cross sectional study longitudinal studies must be conducted to generate rich data collected over a period of time which will give more insights in the adjustment patterns over a period of time and its impact on the study variables. Since the data was collected from the four cities, generalizability of the findings to other expatriates working in worker cities in United States of America is problematic as United States of America is a big country with many sub cultures co existing.

\section{DISCUSSION AND CONCLUSION}

In the global scenario most of the organizations have understood the importance of on going training needs for the expatriates to meet the challenges off shore. Even though pre departure training is conducted the impact of it is minimal as compared to the training imparted on a regular basis. Because its only at the site employee faces the reality (Lane \& Distefano J. J.: Maznevski, 2006).

With globalization the boundaries of work have no limit and the employees are expected to learn and adapt to different scenarions to function effectively without criticizing the environment or working conditions. The MNCs should focus on global management i.e. the process of developing strategies, design, and operating systems and working with people around the world to ensure sustained competitive advantage.

It is felt that employee needs to be more broad minded and learn to adapt to any working environment. For this one the most important thing is employee should have high level of emotional intelligence. Absence of this and employee cannot get adapted to different working environment. Employee may have high level of IQ but the level of EQ is more important. So that he can understand it, and yet still to make sense of the world to act appropriately (Lane \& Distefano J. J.: Maznevski, 2006). Enhancing of emotional intelligence would make the employee more adaptable to the new culture and adjust to any scenarios. (Black \& Grehersen, 1999) argue that "making executives aware that they will face different business and social customs is not sufficient, because awareness does not necessarily bring competence in the host culture" as cited in (Lane \& Distefano J. J.: Maznevski, 2006). So developing cross cultural competency take more than mere providing country statistics.

Pre departure trainings sessions would help an employee to assimilate the environment in which he is going to work and the culture and surroundings. But the organizations should take effort to provide continuous regular training on arrival and after joining to orient to the new work culture and environment. It was learnt that ten to twenty percentage of the employee return back to country within three months due to non adaptability factor. It's the absence of mentor or counselor which leads to such a scenario. Imparting of cross cultural training would enable to overcome the bamboozlization state of the employee which will neutralize stress (Lane \& Distefano J. J.: Maznevski, 2006).

With globalization we are getting into boundary less scenarios. Technically all want to enhance and grow. To facilitate this we need to have an environment where the climate is conducive. To facilitate this we should be able to understand each other cultures and value system. An employee who is assigned on an international assignment can notsucceed without deep understanding of national cultures in which they work. It is important for the employees and the MNCs that understanding a different culture is a never ending process. The employee must prepare themselves by studying more about business etiquette and understanding the national culture. The IT employees must be sensitive and observe the environment and people continuously and adjust their behaviour to work effectively in the host country. They should change the mindset from looking at culture as a potential obstacle and seek opportunity and take advantage of the working in cross cultural settings. The MNCS should train the employees to develop management skills to be successful in more than one culture.

Due to globalization and intense completion on the global IT industry, the MNCS are using international assignments to remain competitive and gain edge over the competitors. The MNCs success and survival depend on its ability to develop technically qualified and self-motivated employees who are capable enough to performance in cross cultural settings. This study shows that organizations support positively effects the expatriate performance in the international assignment. The study also shows that the expatriate psychological wellbeing depends on the perceived family support. MNCS should also focus on the family adjustment as a whole than simply concentrating on the individual employee in the international assignments. The MNCs should facilitate smooth adjustment of the expatriate and the immediate family by providing career support, financial support and adjustment support in the host culture. Orientation programs for the accompanying spouses might ease the transition for the expatriate employee in the host culture and help in overcoming the initial cultural shock to the new cultural settings. If the MNCs pay little attention to the support provided, will adversely impact the expatriate performance and psychological welling. As predicted, the empirical evidence shows that organizational support received determines the extent of work performance of the expatriates in international assignment. This study further shows that there is a relationship between the perceived expatriate supporting practices and performance. The study shows that employee's perception of the organization support will be reciprocated in the form of commitment to the organization and effective performance. Employees' perceptions of the organization's dedication to their well-being in light of support and career planning contribute to enhancing expatriates' job performance. This study shows the contribution of the individual competencies like emotional, cultural intelligence and organizational support on expatriate performance. 


\section{REFERENCES}

1. Borman, W. C., \& Motowildo, S. J. (1997), A Theory of individual differences in task and contextual performance. Human Performance, 10(2), 71-83.

2. Blumberg, B., Cooper, D. R., \& Schindler, P. S. (2011), Business research methods (3rd European ed.). London, United Kingdom: McGraw-Hill Education.

3. Chen, A. S., Lin, Y., \& Sawangpattanakul, A. (2011), International Journal of Intercultural Relations The relationship between cultural intelligence and performance with the mediating effect of culture shock: A case from Philippine laborers in Taiwan. International Journal of Intercultural Relations, 35(2), 246-258. doi:10.1016/j.ijintrel.2010.09.005.

4. Earley, P. C., \& Ang, S. (2003), Cultural intelligence: Individual interconnections across cultures . Stanford, California: Stanford University Press.

5. Eisenberger, R., Stinglhamber, F., Vandenberghe, C., Sucharski, I. L., \& Rhoades, L. (2002), Perceived Supervisor Support : Contributions to Perceived Organizational Support and Employee Retention, 87(3), 565-573. doi:10.1037//0021-9010.87.3.565.

6. Ghauri, P., \& Gronhaug, K. (2005), Research methods in business studies (3 ed.). England: Prentice Hall Financial Times.

7. Harrison, D. A., Shaffer, M. A., Harrison, D. A., \& Shaffer, M. A. (2007), Mapping the criterion space for expatriate success : task- and relationship-based performance, effort and adaptation success : taskand relationship-based, 5192(September 2015). doi:10.1080/09585190500220648.

8. Hechanova, R., Beehr, T. A., \& Christiansen, N. D. (2003), Antecedents and Consequences of Employees Adjustment to Overseas Assignment: A Meta-analytic Review, 52(2), 213-236.

9. Kothari, C. R., \& Garg, G. (2013), Research Methodology. New Delhi, India: New Age International Publishers.

10. Kraimer, M. (2004). An Examination of Perceived Organizational Support as a Multidimensional Construct in the Context of an Expatriate Assignment. Journal of Management, 30(2), 209-237. doi:10.1016/j.jm.2003.01.001.

11. Lane, H. W., \& Distefano J. J.: Maznevski, M. L. (2006), International management behavior: text, readings, and cases (5 ed.). Malden, MA, USA: Blackwell Publishing.

12. Maylor, H., \& Blackmon, k. (2005), Researching business and management. London: Palgrave macmillian.

13. Osman-gani, A. M., \& Rockstuhl, T. (2008), Antecedents and Consequences of Social Network Characteristics for Expatriate Adjustment and Performance in Overseas Assignments : Implications for HRD, 7(1), 32-57. doi:10.1177/1534484307312182.

14. Wong, C. S., \& Law, K. S. (2002), The effects of leader and follower emotional intelligence on performance and attitude:An exploratory study. The Leadership Quarterly, 13, 243-274.

15. Wua, P. C., \& Ang, S. H. ( 2011), Singapore, The impact of expatriate supporting practices and cultural intelligence on cross-cultural adjustment and performance of expatriates in Singapore. The International Journal of Human Resource Management, 22(13), 2683-2702.

16. Wu, P., \& Ang, S. H. (2011), The impact of expatriate supporting practices and cultural intelligence on cross-cultural adjustment and performance of expatriates in Singapore, 5192(September 2015). doi:10.1080/09585192.2011.599956.

17. Zikmund, G. W. (2003), Business research methods. New Delhi: CENGAGE learning. 